$\xi=-1$

\title{
A Comparative Study of the Effect of Alcoholic Extract of Tur- meric Plant in Inhibiting the Growth of Candida Albicans
}

\author{
Safaa M. $\operatorname{sultan}^{1 *}$, Ali M.Saady ${ }^{2}$, Maha E Irzoqy ${ }^{3}$ \\ ${ }^{1}$ Northern Technical University,Technical Institute Hawija \\ ${ }^{2}$ Northern Technical University, Technical Institute mosul \\ ${ }^{3}$ Ministry of Education, mosul , Iraq \\ *Corresponding author E-mail: safaahawija@gmail.com
}

\begin{abstract}
Turmeric is one of the most widely used spices in nature. It contains many health benefits that are countless. Chinese medicine has been used in the preparation of various medicines because it contains curcumin. The inhibitory activity of the turmeric extract for the fungus of Candida bicans, which causes oral salivary disease, was compared with the inhibitory effect of some antibiotics against this fungus In this study, isolating and diagnosing this type of fungal disease was obtained by obtaining an oral smear from children with oral diarrhea. Two methods were used to detect the process of inhibition by the alcohol extract of turmeric I was by the method of propagation and the second was using the ts immersed in the extract of the turmeric plant turmeric for 48 hours. The results and the physiological and biochemical tests of the survey used in the study showed that the isolation is due to the yeast of Candida albicans. It was also found that the extract of alcohol for turmeric plant showed an inhibitory effect of the growth of this type of fungus by increasing concentration in both ways. The concentration of $16 \mathrm{mg} / \mathrm{ml}$ was found to inhibit the growth of Candida and then $8 \mathrm{mg} / \mathrm{ml}$ and finally $4 \mathrm{mg} / \mathrm{m}$ compared to the fungal antagonists Nystatin, fluoconazole and ketoconazole It has been shown that turmeric is very useful in the treatment of bacterial and fungal infections and can be counted as an antibiotic because it contains curcumin.
\end{abstract}

Keywords: Antibiotic, Curcumin, Candida albicans, fungal infections,oral salivary disease,Turmeric extract.

\section{Introduction}

Turmeric is the scientific name of it (Curcoma Longa) of the Zingberaceae family and its native habitat grows in the tropics and increases in East India. Turmeric is a herbaceous plant with roots, but its annual leaves rise up to a meter (Castellote , 2013), have large tubers growing near the surface of the earth yellow color and turmeric tubers are sold in the markets either in their condition or yellow powder (Dovigo, 2013). Turmeric is contains a group known as Curcuminds and the most important compounds is Curcumin, which is separated commercially and is currently sold as a pure compound, which is responsible for almost the effects of pharmacological turmeric and also gives the yellow color characteristic of turmeric and also contains a compound of Demethoxy Cuecumin (Bisdemethoxy Cuecumin), instead of containing turmeric on oil oils at a rate of $4.2-14 \%$. This oil consists of about 50 compounds. This group is known as Turmerons and other components. Pilot oil 13.9 B-bisbolene 7.6 Maersen (Myrecene) 6.9\% Cineole 6.4 Thymol and Alfa-Far Yen (Alfa-farnedene) as well as Alzenjberen (Zingiberene) and Altaomiron (Turmerone) contains turmeric from the resin of the pilot who is known as (Oleo-resin) and a constant material once oil protein starch and cellulose associate (Dias Ribeiro, 2013). Turmeric Uses: - Turmeric is used for the treatment of stomach ulcers, diarrhea, sinusitis, and liver diseases. It also prevents blood clotting and lowers serum sugar and cholesterol levels. Topical Turmeric is used to treat wounds, insect bites and skin diseases such as eczema, scabies and fungi (Fallah, 2010). Face and talcum An antioxidant property that works to reduce lipid peroxidation in tissues Curcumin and curcumin have anti-cancer effect through antioxidant properties and its equivalent effect of free radicals. It also stimulates natural antioxidants in the body and works to increase the level of Clutapathon Glutathion $(\mathrm{OSH})$ and thus we note that it helps (Bensadoun,2011) Oxide in the removal of the toxic effect of carcinogens and mutants where the alcohol extract inhibited the growth of Hep-2 cancer cells and did not affect the normal cells as well as Curcumin inhibited the development of bladder cancer cells of rats As it has increased the gene P53 and thus increase the formation of proteins responsible for self-programmed death of cancer cells and also possesses turmeric properties to protect the oxide and the rest of the body of the carcinogenic effect of aflatoxin as it reduces the peroxide and the level of enzymes Abaritt Amenotrasfirter (Aspartate aminotavsferase) and serum creatinine content in the works on how to raise the effectiveness of antioxidants enzymatic and nonenzymatic also found that the extract curcumin works to reduce alcohol from the decomposition of the red blood cells caused by treatment aflatoxin outside of the living body (Patchva,2012).

Candida albicans it is one of the types of microscopic fungi that are present in the human body without causing any harm (Gupta, 2016). It is a living organism with a fake cell that propagates in a non-sexual way and is derived from the products of the chemical reactions that occur inside the body or on the dead cells or the sugar in the food. Candida fungus is found naturally in the human body, in addition to the skin and mucous membranes of the body without causing infection. If a change in the internal environment of the body or weakened immunity, these fungi will multiply greatly causing infection and infection (Huang, 2016). 


\section{Materials and Methods}

An easy way to comply with the paper formatting requirements is Preparation of medicinal plant for extraction: The collection of medicinal plants Turmeric used in the study from the local markets in the form of sticks and was grinded to obtain a fine powder and was packaged plastic bags until used to prepare alcohol extracts Preparation of turmeric extract of alcohol: - The method Babaii \& Zamaninejad 2016 in the preparation of the anthrax extract of the turmeric used in the study, by dissolving in alcohol, dissolving 20 grams of turmeric in 200 grams of alcohol ethylene concentrate $95 \%$, or (1:10) weight size and then mixed mix Using a mixer for five minutes and for intermittent periods. Then put it in a closed sealant and stir in the shaker for two hours. The mixture was then sprayed through several layers of the shas. It was centrifuged at $5000 \mathrm{rpm}$ for 10 minutes and again injected with a bochner funnel Using filter paper (Wattman N0-2) under discharge and after filtration processes put The rotary evaporator (Rotary Vacum evaporator), supplied by the English company Electrothro thermal, which works on the basis of coagulation under pressure and temperature not more than $40 \mathrm{~m}$. After evaporating the original alcohol in the mixture completely, a thick layer of extract was obtained Complete the drying with the Lyufhi lizir under $50 \mathrm{~mL}$ pressure and then save the diluted volume extract in plastic boxes with a tightly sealed lid until use (Moghadamtousi, 2014).

Sterilization of alcoholic extracts:(1) gm extract of the turmeric medicinal plant in $5 \mathrm{ml}$ of Ethylen glycol to obtain a concentration of $200 \mathrm{mg} / \mathrm{ml}$ as a standard concentration for the preparation of the dimming and then sterilization was sterilized by $62 \mathrm{~m}$ for ten minutes and this standard concentration was considered a source of preparation of the dimming Which were used in the study of this research and according to the mitigation equation;

$\mathrm{N} 1 \mathrm{~V} 1=\mathrm{N} 2 \mathrm{~V} 2$

Three different concentrations were prepared, including $4 \mathrm{mg} / \mathrm{ml}$, $8 \mathrm{mg} / \mathrm{ml}$ and $16 \mathrm{mg} / \mathrm{ml}$ of turmeric extract (Fakoya, 2010).

Antibiotics:The antibiotic ts used in the study are manufactured by Bioanalysis Ltd Turkey and are shown with their concentrations in Table (1) (Babaii, 2016).

Table 1: Types and concentrations of antibiotics used in the study

\begin{tabular}{|l|l|}
\hline Antibiotic & Concentration $(\mathrm{mg} / \mathrm{m})$ \\
\hline Nystatin & 30 \\
\hline Fluconizole & 10 \\
\hline Ketoconazole & 10 \\
\hline
\end{tabular}

Isolation and diagnosis:In this study, a sample was taken from a child with oral sap as shown in Figure 1. The sample was placed on dishes containing the center of the acrobide acar in the planning method. Three replicates were performed on the previously mentioned medium to get rid of the contamination process that may occur during this process and incubated the dishes for 24 hours under ${ }^{\circ} \mathrm{C}$ The farms that appeared in the middle were identified by their phenotypic characteristics and microscopic characteristics (Fakoya, 2016).

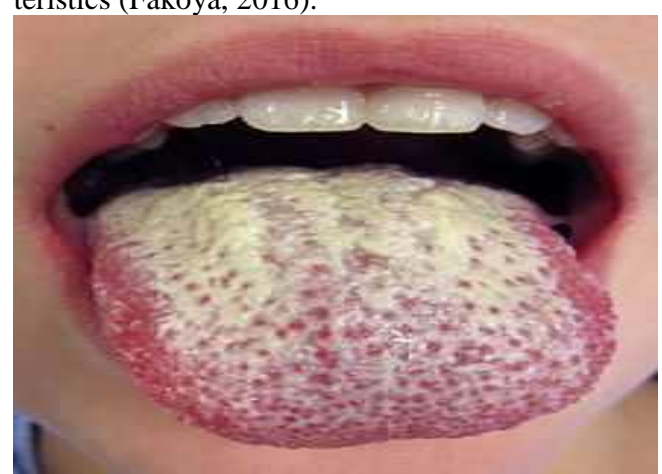

Fig. 1: the shape of the sample containing Candida albicans.
Test the inhibitory activity of the turmeric extract

The inhibitory efficacy of antibiotics was studied by cultivating Candida albicans on the Sabroid agar medium by brushing with a laminar. The dishes were placed in the incubator for 15 minutes. Antibody tablets were placed on the dishes with sterile forceps and incubated for 48 hours (Sarah, 2016).

The inhibitory efficative of the turmeric extract was tested in two ways:

1- Method of discs: The Kirby Bauer method was used to complete this test. The Sabroid Broth liquid medium was prepared with a concentration of 108 cells / $\mathrm{mL}$ in comparison with the McFarland tube 1 and $0.1 \mathrm{ml}$ of fungal lactate was injected with a sterile polarity scanner on a dish containing the hard corn flour in a brushwise manner. For a period of half an hour at $37^{\circ} \mathrm{C}$ for the purpose of drinking the medium. The first method was used to observe the inhibition by placing a $6 \mathrm{~mm}$ diameter of Wattman paper with the different concentrations of the extracts by immersing them in these extracts for 24 hours and fixing the discs using sterile forceps on the surfaces of the fertilized dishes and incubated For 48 hours b $37 \mathrm{~m}$ jolt after the end of the incubation was observed and measured diameters of inhibition around the saturated disks Palmstkhals alcohol turmeric (Singh, 2014)

2: - Method of publishing

The inhibitory effect of the alcoholic extract on the yeast of Candida albicans was carried out with specific sizes of each sterilized extract to specific sizes of the food medium of the hard corn flour before hardening with the shake to obtain concentrations $(4,8,16)$ $\mathrm{mg} / \mathrm{ml}$, After the hardening of the center, a sample of Candida albicans yeast was taken and planted in the previously prepared dishes in a planning manner. The dishes were incubated for 48 hours at a temperature of $37^{\circ} \mathrm{C}$. The cultivation process was incubated in an inverted position Under sterile conditions, the results were taken By observing colonies growing on the dishes (Boon, 2013).

\section{Results and Discussion}

Isolation and diagnosis: In the phenotypic assay, colonies were grown on a container plate on the center of the hard corn flour in white colonies of a larger size than the colonies of the bacteria and with a simple convexity as shown in Fig(2) (Boon, 2013).

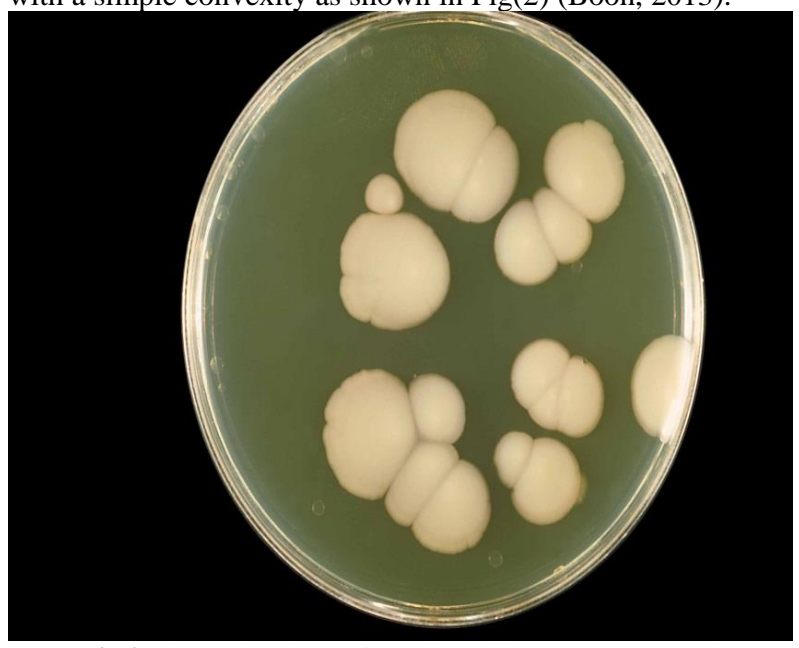

Fig 2: shows the shape of Candida albicans on corn meal agar

In the microscopic examination, the bacterial tube formation was observed by planting in the serum and incubating it for 3 hours at a temperature of $37^{\circ} \mathrm{C}$ and the appearance of the cells under 40 magnification as shown in Fig(3) (Tapiwa ,2017) (Xiaowen,2016). 


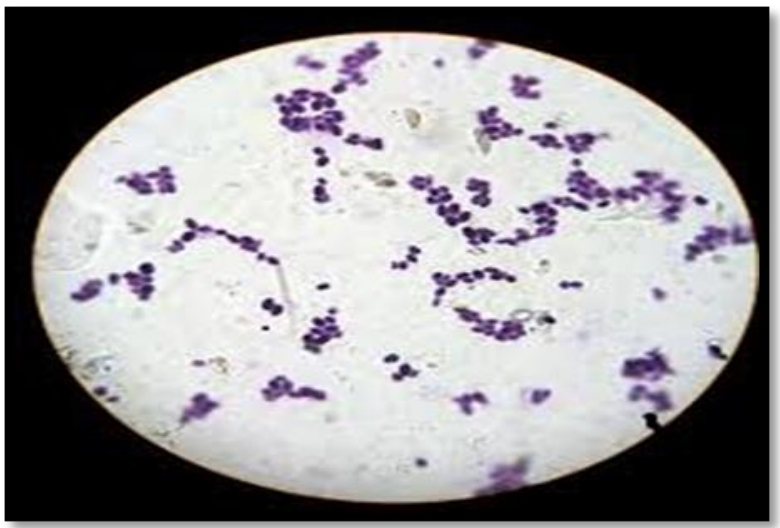

Fig.3: shows the shape the cell of Candida albicans ander the microscope

The inhibitory effect of some antibiotics on the fungus of Candida albicans was studied. Table 2 shows the inhibitory effect (inhibition diameter in $\mathrm{mm}$ ) of the antibiotic on candida albicans (Khosravi, 2011).

Table 2: shows the inhibitory effect (inhibition diameter in $\mathrm{mm}$ ) of the antibiotic on candida albicans

\begin{tabular}{|l|l|}
\hline Antibiotic & Inhabtion zone \\
\hline Nystatin & 11 \\
\hline Fluconizole & 14 \\
\hline Ketoconazole & 17 \\
\hline
\end{tabular}

also studied the effect of alcohol extract with its various concentrations on the inhibition of the growth of candida albicans constitute a concentration of $4 \mathrm{mg} / \mathrm{ml} 8 \mathrm{mg} / \mathrm{ml} 16 \mathrm{mg} / \mathrm{ml}$ of alcoholic extract of turmeric plant as shown in the table 3 (Methaq, 2016) The highest inhibition was at $16 \mathrm{mg} / \mathrm{ml}$ if the inhibition diameter was $17 \mathrm{~mm}$ followed by $8 \mathrm{mg} / \mathrm{ml}$ and the diameter was $14 \mathrm{~mm}$ and finally the concentration was $4 \mathrm{mg} / \mathrm{ml}$ with a diameter of 12 $\mathrm{mm}$

Table 3: The inhibitory effect for the turmeric extract of turmeric plant \begin{tabular}{|l|l|}
\hline Concentration of the alcoholic extract of turmeric plant & Inhabtion zone \\
\hline 4 .
\end{tabular}

\begin{tabular}{|l|l|}
\hline $4 \mathrm{ml} / \mathrm{ml}$ alcoholic extract & 12 \\
\hline $8 \mathrm{ml} / \mathrm{ml}$ alcoholic extract & 14 \\
\hline $16 \mathrm{ml} / \mathrm{ml}$ alcoholic extract & 16 \\
\hline
\end{tabular}

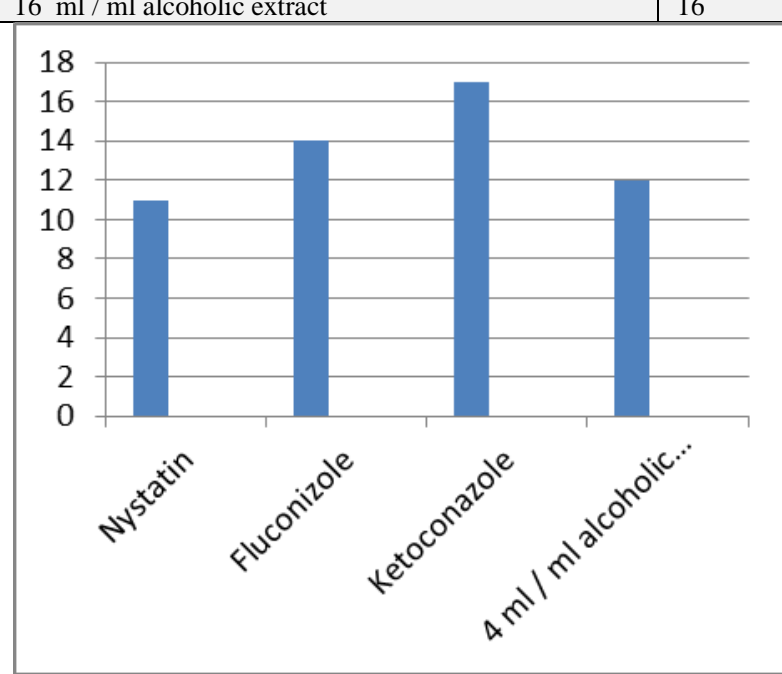

Fig. 4: shows the inhibition zone of the alcohol extract at a concentration of $4 \mathrm{mg} / \mathrm{ml}$ compared to antibiotics

This figure 4 noticed the concentration $4 \mathrm{mg} / \mathrm{ml}$ had been inhibition effect similar to that antibiotic nystatin on the growth of the candida albicans.

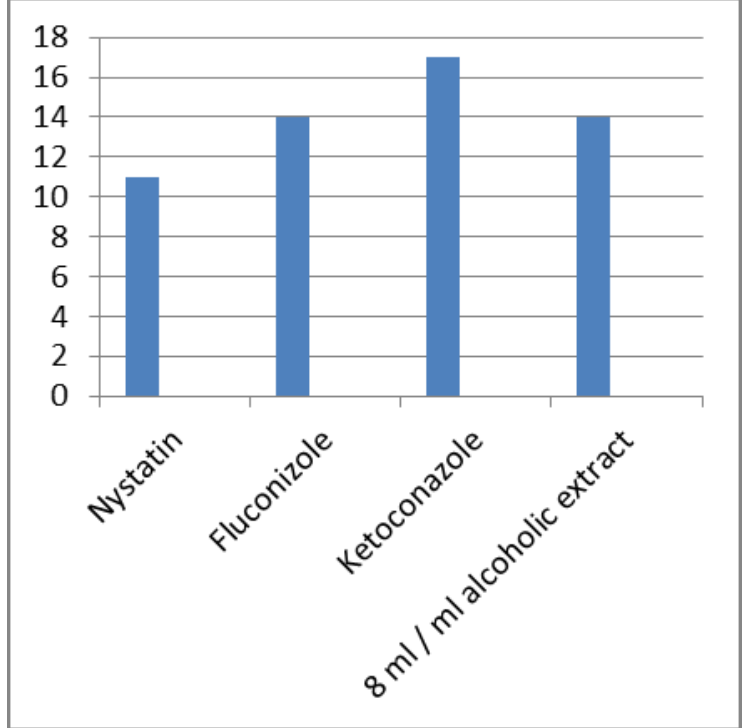

Fig.5: shows the inhibition zone of the alcohol extract at a concentration of $8 \mathrm{mg} / \mathrm{ml}$ compared to antibiotics

From figure 5, it can be noted that the concentration of $8 \mathrm{mg} / \mathrm{ml}$ had been inhibition effect better than the concentration of $4 \mathrm{mg} / \mathrm{ml}$ and the antibiotic nystatin on the growth of the candida albicans. This is due to the increases of the curcumin in alcoholic turmeric extract. (Boon, 2013).

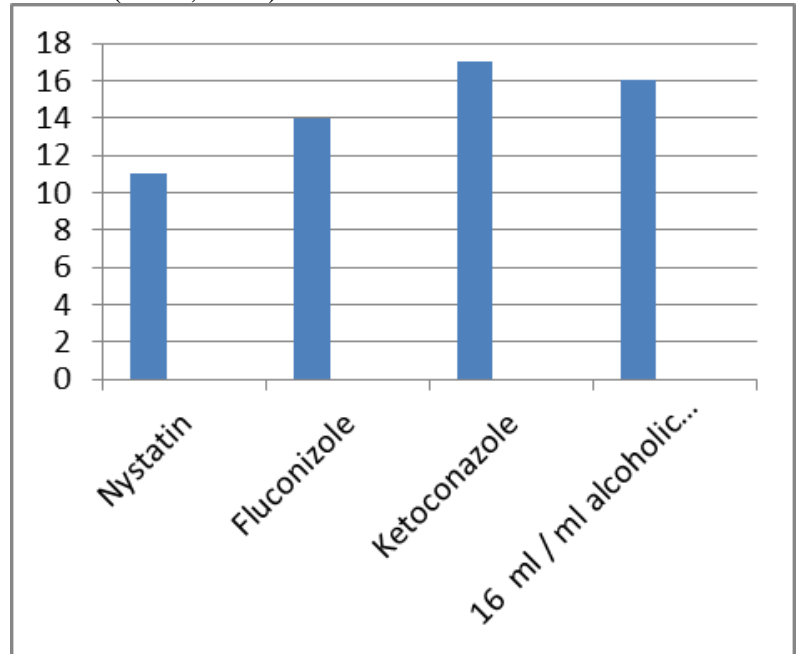

Fig. 6: shows the inhibition zone of the alcohol extract at a concentration of $16 \mathrm{mg} / \mathrm{ml}$ compared to antibiotics

Figure (6) showed that the concentration of $16 \mathrm{mg} / \mathrm{ml}$ had a preference in its inhibitory role on Candida albicans compared to the antibiotics used in the study followed by the concentration of $8 \mathrm{mg}$ $/ \mathrm{ml}$ and finally the concentration of $4 \mathrm{mg}$

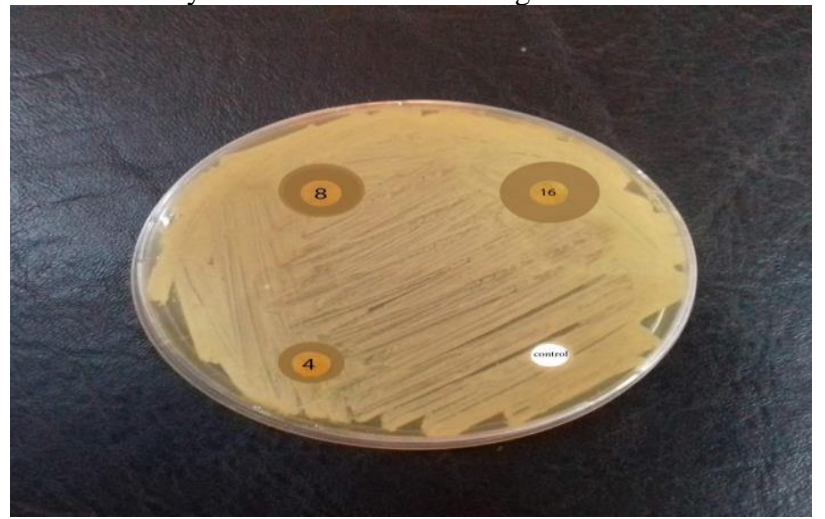

Fig. 7: shows the increase in the diameter of inhibition by increasing the concentration of the alcohol extract on the fungus of Candida 
From figure 7 it is clearly obvious that the highest diameter for inhibition of fungus was at the concentration of $16 \mathrm{mg} / \mathrm{ml}$ as it was $17 \mathrm{~mm}$ followed by the concentration of $8 \mathrm{mg} / \mathrm{ml}$ and finally the concentration of $4 \mathrm{mg} / \mathrm{ml}$

It is possible to explain the existence of this gradual increase in the diameter of the growth of the fungus with increasing concentration, the possibility of binding the active substance in the extract of alcohol with receptors that exist on the surface of the cell and therefore may cause an imbalance that causes the contraction of protoplasm and the entry of materials have the ability to influence the events In-vitro. This corresponds to what Babaii N\& Zamaninejad S found in 2016. (Nassir, 2010) (Hussain, 2011).
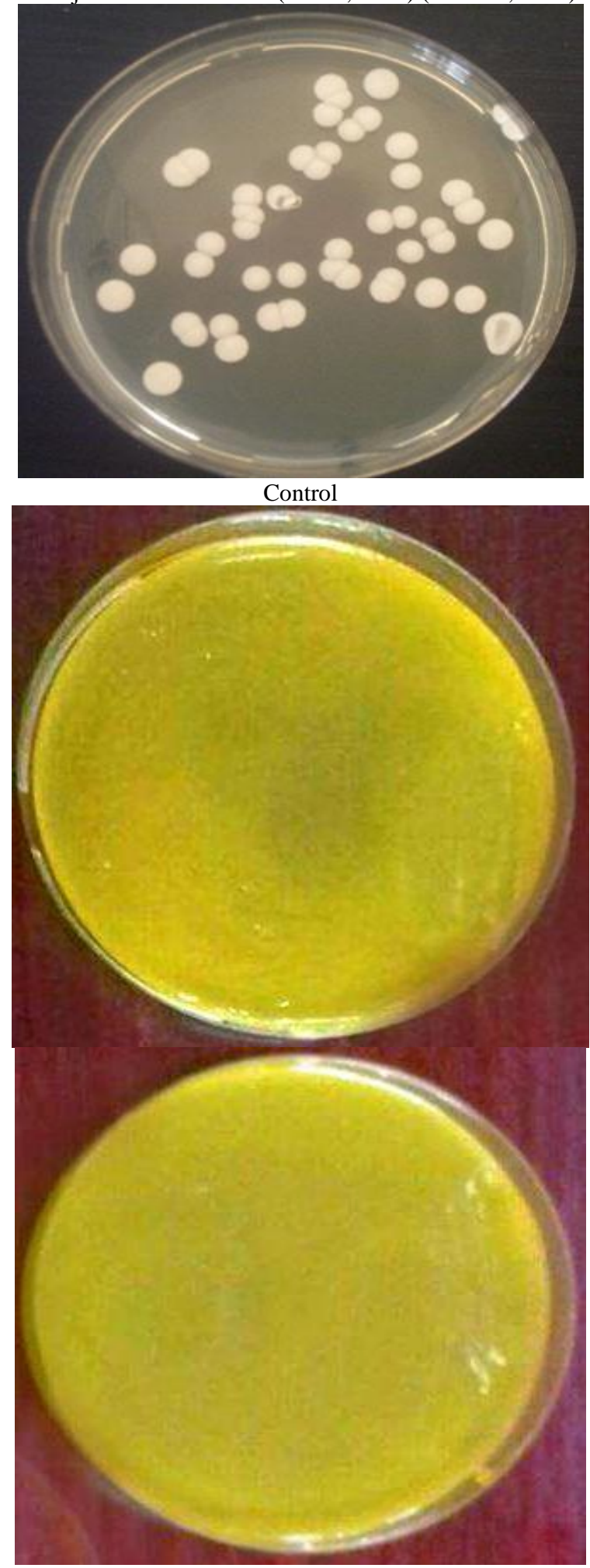

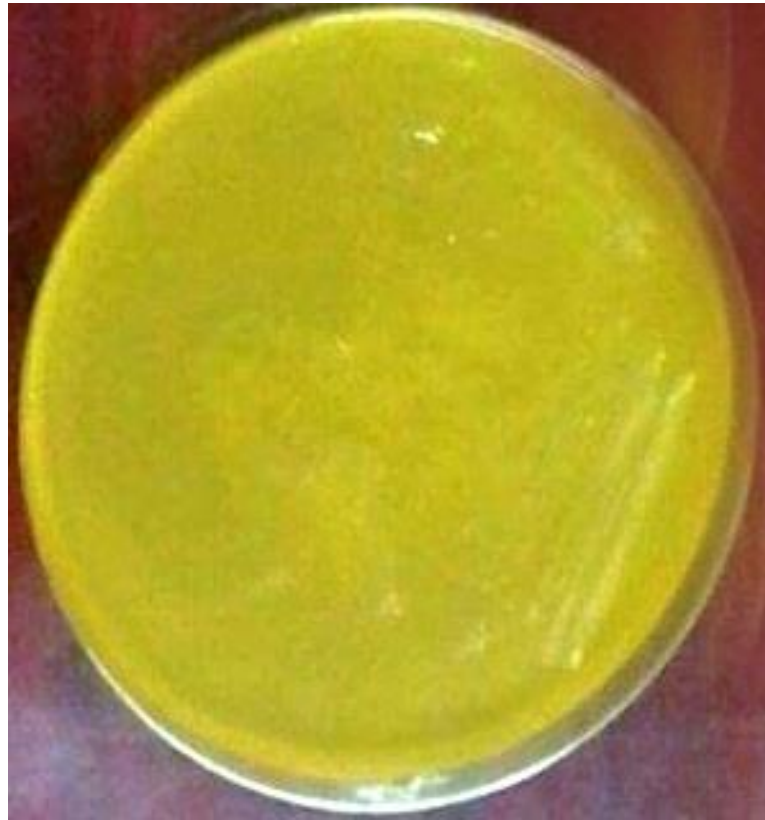

$(4 \mathrm{mg} / \mathrm{ml}) \quad(8 \mathrm{mg} / \mathrm{ml})(16 \mathrm{mg} / \mathrm{ml})$

Fig. 9: shows the test of the inhibitory effect of various concentrations of the extract of turmeric plant turmeric method of dissemination.

The results in figures 9 show that the inhibitory effect of the alcohol extract of the medical turmeric on the fungus of Candida bicans, which affects the oral cavity (oral saliva) within the studied concentrations (Singh, 2013), the highest inhibition was the concentration of $16 \mathrm{mg} / \mathrm{ml}$ as the growth rate of the colonies is very low followed The concentration is $8 \mathrm{mg} / \mathrm{ml}$ and $4 \mathrm{mg} / \mathrm{ml}$ as comparing to control in figure 9. This is due to the fact that the alcohol extract of turmeric contains an active substance (Saroj, 2013) (Agaoglu, 2015), the most prominent phenolic compounds that have an effect against the fungus (where the aromatic ring in these compounds contains Hydrox Group $(\mathrm{OH})$ as it tends to be a hydrogenase with the side that has high efficiency of the enzymes and thus lead to a change in the size of these enzymes and changes in their properties and thus becomes ineffective in the cell leads to a halt in the biological path in certain locations in the cell (Xiaowen, 2016) On the other hand, we observe that the compounds affect the balance of cellular content and lead to damage within the cell by making clear some of the proteins on the cell membrane as these compounds are absorbed by the surfaces of proteins and lead to the formation of complex Shape and volume of leading proteins To a change in the characteristics and thus change in the nature of its work stops one vital path in the cell, leading to a halt in the growth or death of this cell by the other foreigners, (Khosravi, 2011) (Dovigo, 2013) note the chemical composition of the medical turmeric contains turmeric, alkaloids, resins, terbins and tannins, which have an antimicrobial effect These compounds act on the deposition of proteins associated with the cellular membranes of Candida albicans and thus affect the process of entry and exit of nutrients into and out of the cell as well as the formation of complexes with polysaccharides and their effect on enzymes as affect the terpenes On the membrane of the cell, disrupting the process of entering and exiting materials to and from the cell (Boon, 2013) ( Dias, 2013).

\section{Conclusion}

We conclude from this study that the extract of turmeric alcohol has an inhabtion effect on the isolated Candida albicans, which is isolated in this study. Obtaining an inhibitory agent for this type of fungus which causes oral sputum is an issue that may be somewhat important, especially the superiority of the extract on certain antimicrobial agents, including the antibiotic nastatin, which opens the door to other studies in order to ascertain more accurate- 
ly the appropriate concentration of Within the body of the organism using laboratory animals, he preferred to do other analytical studies to know the effective compound in turmeric plants towards other bacteria and perhaps using other solvents to extract the active substance and thus fix the therapeutic ability of this material accurately and then $\mathrm{M}$ Which opens the door to other studies to more accurately ascertain the appropriate concentration of showing inhibitory effectiveness within the body of the organism using laboratory animals. In addition to other analytical studies of the effective compound in turmeric towards other bacteria and possibly using solvents To extract the active substance and thus to fix the therapeutic potential of this material accurately and then be able to be used as a treatment for the adaptation of sensitive germs.

\section{Acknowledgement}

The author Safaa M. would like to thank the Northern Technical University,Technical Institute Hawija and Ministry of Education. Thanks to all who submitted the assistance to complete this work especially Dr.Omer Kh.and Falah H.

\section{References}

[1] Agaoglu, Dostbil, And Alemdar,S.; N.“Antimicrobial effect of seed extract of cardamom (Elettariacardamomummaton)"YYU veterinerfakultesi dergisi .74(2):113-123.2015

[2] An Evaluation of the Effect of Sodium Bicarbonate on Morphogenesis and Comparison with Pooled Human Serum, Hindawi BioMed Research International, p 1-5.

[3] Babaii N\& Zamaninejad S, Inhibitory Effect of Curcumin on Candida-albicans compared with Nystatin: an in-vitro Study .2016

[4] Bensadoun RJ, Patton LL, Lalla RV, Epstein JB. Oropharyngeal candidiasis in head and neck cancer patients treated with radiation: update 2011. Support Care Cancer. 2011; 19:737-744.

[5] Boon Ping Haw and other(2013), Phenotyping Identification of Candida albicans for the Production of In House Helicase for Nucleic Acid-Based Detections for Fast Diagnosis, Research Journal of Pharmaceutical, Biological and Chemical Sciences , ISSN: 09758585 , 576- 583.

[6] Boon, p.h.,and other (2013), Phynotyping identification of candida albicans for the production of in house helicase for nucleic acidbased detections for fast diagnosis. 2th ed. Pulau pinang . Malysia

[7] Castellote L, Soriano Y, Clinical and microbiological diagnosis of oral candidiasis. J Clin Exp Dent. 2013; 5(5):279-286.

[8] Dias Ribeiro AP, Pavarina AC, Dovigo LN, Brunetti IL et al. Phototoxic effect of curcumin on methicillin-resistant Staphylococcus aureus and L929 fibroblasts. J Lasers Med Sci. 2013; 28:391-398.

[9] Dovigo LN, Carmello JC, Souza Costa CA, Vergani CE, Brunett LI, Vanderlei Salvador Bagnato,ets. Curcumin-mediated photodynamic inactivation of Candida albicans in a murine model of oral candidiasis. J Med Mycol (2013) 51 (3): 243-251.

[10] Fakoya and other (2014), possible antimicrobial activity of Morinda lucida stem bark, leaf and root extracts. Sci. Res. Essays., 1(2): 5053

[11] Fakoya and other (2014), Possible antimicrobial activity of Morinda lucida stem bark, leaf and root extracts. Sci. Res. Essays., 1(2): 50-53.

[12] Fallah Hoseini H, Zahmatkesh M, Haghighi M. Aplocations of Curcuma Longa L. in traditional and modern science: a review article. J verbal plants. 2010; 33(9):1-10.

[13] Gupta, S.C., Patchva, S. \& Aggarwal, B.B. Therapeutic Roles of Curcumin: Lessons Learned from Clinical Trials. AAPS J. 2013; 15: $195-218$

[14] Huang L, Zhang J, Song T, Yuan L, Zhou J, Yin H, et al. Antifungal curcumin promotes chitin accumulation associated with decreased virulence of Sporothrix schenckii. Int Immunopharmacol. 2016; 34:263-270.

[15] Hussain, R., A., 2011. Acomparsion of biological and molecular parameters of some candida species sensitive and resistance to some antifungal agents. Athesis. College of science. Kufa university

[16] M. Khosravi Samani,(2011)The effect of Frankincense in the treatment of moderate plaque-induced gingivitis: a double blinded ran- domized clinical trial, Tehran University of Medical Sciences, $\mathrm{p}$ 288-294

[17] Methaq Algabr and other (2016). Screening of Yemeni medicinal plant for antibacterial and antifungal activates. Advances in Natural and Applied Sciences. 8:28-32.

[18] Moghadamtousi S, AbdulKadir H, Hassandarvish P, Tajik H, Abubakar S, Zandi K. A Review on Antibacterial, Antiviral, and Antifungal Activity of Curcumin. J BioMed Research International. 2014

[19] Nassir, Noor Ismaeel.,2010. Incidence of C. albicans isolates from oral and vaginal candidiasis, study of their susceptibility and crossresistance to some antifungal agents.Thesis. College of Medicine / Al-Qadisiya University

[20] Sarah Kidd and other (2016), Description Of Medical Fungi ,Third edition, $\mathrm{p} 37$

[21] Saroj, G.K., Mallika R.k., Sugatha,K., Vivek, H.,2013.Speciation of candida using chromogenic and corn meal agar with determination of fluconazole sensitivity

[22] SC, Patchva S, Koh W, Aggarwal BB. Discovery of curcumin, a component of golden spice, and its miraculous biological activities. Clinical and Experimental Pharmacology and Physiology. 2012; 39(3): 283-299.

[23] Singh S., Kumar,A. and Kumar, A.,2013. Species identification, antifungal susceptibilty testing and genetic variability among Candida species isolated from clinical samples. Journal of drug discovery and therapeutic. 1(3):01-11.

[24] Singh S.and Kumar,A (2013), Species identification , antifungal susceptibilfy testing and genetic variability among Candida species isolated.

[25] Tapiwa Matare and other (2017), Experimental Germ Tube Induction in Candida albicans:

[26] Xiaowen Jiang and other (2016), Effect of Frankincense Extract on Nerve Recovery in the Rat Sciatic Nerve Damage Model. Evidence-Based Complementary and Alternative Medicine,1-8 . 